International Journal of Environmental Research and

\title{
Associations of Lipoprotein Lipase Gene rs326 with Changes of Lipid Profiles after a High-Carbohydrate and Low-Fat Diet in Healthy Chinese Han Youth
}

\author{
Xing-chun Zhu ${ }^{1,2}$, Jia Lin ${ }^{1}$, Qian Wang ${ }^{1}$, Hui Liu ${ }^{1}$, Li Qiu ${ }^{1}$ and Ding-zhi Fang ${ }^{1, *}$
}

1 Department of Biochemistry and Molecular Biology, West China School of Preclinical and Forensic Medicine, Sichuan University, Chengdu 610041, China; E-Mails: zhuxingch@aliyun.com (X.-C.Z.); jiajiahu198247@163.com (J.L.); wangqianhunya@gmail.com (Q.W.); liuhui1913@126.com (H.L.); qinger636783@sina.com (L.Q.)

2 Clinical Laboratory, Nanchong Central Hospital, Second Affiliated Hospital of North Sichuan Medical College, Nanchong 637000, China

* Author to whom correspondence should be addressed; E-Mail: dzfang@scu.edu.cn; Tel.: +86-28-8550-2849; Fax: +86-28-8550-3204.

Received: 19 December 2013; in revised form: 8 April 2014 / Accepted: 14 April 2014 / Published: 23 April 2014

\begin{abstract}
To investigate the effects of a high-carbohydrate and low-fat (HC/LF) diet on plasma lipids and apolipoproteins (Apos) of healthy Chinese Han youth with different genotypes of lipoprotein lipase gene $(L P L)$ rs326, 56 subjects were given a washout diet of $30.1 \%$ fat and $54.1 \%$ carbohydrate for seven days, followed by the HC/LF diet of $13.8 \%$ fat and $70.1 \%$ carbohydrate for six days, with no total energy restriction. Plasma glucose, triglyceride (TG), total cholesterol (TC), high density lipoprotein cholesterol (HDL-C), low density lipoprotein cholesterol (LDL-C), Apo B-100 and Apo A-I were analyzed at baseline and before and after the $\mathrm{HC} / \mathrm{LF}$ diet. The results show that, when compared with before the $\mathrm{HC} / \mathrm{LF}$ diet, only the male G carriers experienced increased HDL-C $(p=0.008)$ and Apo A-I $(p=0.005)$ after the HC/LF diet. Decreased TC in both males and females and increased TG in females were found regardless of the genotype after the HC/LF diet. LDL-C decreased in all the subjects although the decrease was not significant in the female $G$ carriers. These results demonstrate that the $\mathrm{G}$ allele of $L P L$ rs326 associates with the elevated levels of HDL-C and Apo A-I after the HC/LF diet in males of the healthy Chinese Han Youth.
\end{abstract}


Keywords: apolipoproteins; HC/LF diet; high density lipoprotein cholesterol; single nucleotide polymorphism; lipoprotein lipase

\section{Introduction}

Atherosclerosis (AS) and related vascular diseases are the leading causes of death all over the world [1]. Previous studies have indicated that perturbed concentrations of plasma lipids and apolipoproteins (Apos) are important risk factors for coronary artery disease (CAD) [2,3]. Hypertriglyceridemia (HTG), characterized by elevated plasma levels of triglyceride (TG) and lowered plasma concentrations of high density lipoprotein cholesterol (HDL-C), contributes to the increased risk of CAD $[4,5]$. It has been reported that HTG can be induced by high-carbohydrate and low-fat (HC/LF) diets [6]. However, evidences showed that although more than $67 \%$ of dietary energy was derived from carbohydrate [7], there were lower prevalence and mortality of CAD in Chinese population [8,9]. It is generally believed that these observations are the reflection of their living environments and genetic backgrounds, and suggest the interactions of environmental and genetic factors on modulating lipid metabolism and on development of CAD.

A key protein involved in the hydrolysis of serum TG packaged in lipoproteins containing Apo B is lipoprotein lipase (LPL) [10]. Serum LPL activity and mass are associated with TG and HDL-C [11,12]. Available data have indicated that the polymorphisms of LPL gene $(L P L)$ are related to the disparity of serum lipid profiles and the risk of CAD [13-15]. The latest genome-wide association (GWA) study has identified that rs326 in $L P L$ intron 8 is strongly associated with serum TG and HDL-C levels in 4,192 Chinese subjects aged from 40 to 80 years old [16]. Another study revealed that rs 326 was involved in longitudinal changes of serum TG and HDL-C levels. The minor allele G of rs326 was associated with slowing down a trajectory in both increasing TG and decreasing HDL-C during 20 years of follow-up [14].

Although the risk of CAD has been steadily increasing in younger populations over the past few decades [17], nearly all of the previous studies on carbohydrate-induced HTG have been focused on middle-aged or senior subjects, as CAD is diagnosed primarily after 45 years of age [18]. Much less efforts have been made in studying the effect of interactions of diets and genetic factors on lipid profiles in young healthy subjects. Therefore, in the present study, a washout diet and the HC/LF diet were used to investigate whether interactions of $L P L$ rs326 with diets would be associated with the changes of lipid profiles in a healthy young Chinese Han population.

\section{Subjects and Methods}

\subsection{Ethics Statement}

The study protocol was approved by the Human Research Ethics Committee of Sichuan University and conducted with the understanding, and each of the subjects has signed the informed consent. 


\subsection{Subjects}

Volunteers were recruited via advertisements seeking healthy young students in West China Medical Center, Sichuan University. A total of 209 university students aged 20-30 years were recruited and 60 of them who met the recruitment criteria described previously [19] entered the study. Briefly, all of them were apparently healthy as indicated by the medical questionnaire, physical examination and laboratory tests. They were not taking any lipid-lowing drugs or hormones, not consuming alcohol, and not smoking. All of them were Chinese Han people and asked to maintain their sleeping and physical activity in a constant manner during the study period. Fifty-six of these (27 males and 29 females) completed the study and the other four participants did not for personal reasons.

\subsection{Study Design}

Previous studies indicated that serum TG reached a new steady state and remained constant throughout the period of the diet after a 5-7-day HC/LF diet [20,21]. Meanwhile, a short-term dietary intervention can result in a rapid reversal of metabolic and physiological indexes [22]. As a result, we designed a regime of a 7-day washout diet followed by a 6-day HC/LF diet intervention in the current study.

\subsection{Diets}

Breakfast, lunch and dinner were provided by the Department of Nutrition, West China Hospital, Sichuan University. Each diet was designed to have constant ratios of proteins, fats, and carbohydrates to total energy. As reported before [19], the percentage of proteins, fats and carbohydrates in the washout diet were $15.8 \%, 30.1 \%$ and $54.1 \%$ while in the HC/LF diet, the proportions were $16.2 \%, 13.8 \%$ and $70.1 \%$, respectively (Table 1). All the meals were prepared with local foods. The participants were instructed to eat to their satisfaction as usual at each meal and not to have any other food or drink except water.

Table 1. Composition of the washout diet and the HC/LF diet.

\begin{tabular}{lcc}
\hline \multicolumn{1}{c}{ Ingredients } & Washout diet & HC/LF diet \\
\hline Protein (\% of total energy intake) & $15.8 \pm 1.8$ & $16.2 \pm 1.6$ \\
Total fatty acids (\% of total energy intake) & $30.1 \pm 3.6$ & $13.8 \pm 1.4$ \\
Saturated fatty acids & $7.5 \pm 0.9$ & $3.6 \pm 0.5$ \\
Monounsaturated fatty acids & $16.1 \pm 1.4$ & $7.3 \pm 0.8$ \\
Polyunsaturated fatty acids & $6.4 \pm 1.5$ & $2.8 \pm 0.3$ \\
Carbohydrate (\% of total energy intake) & $54.1 \pm 2.4$ & $70.1 \pm 2.8$ \\
Polysaccharide & $54.1 \pm 2.4$ & $65.7 \pm 1.3$ \\
Monosaccharide and disaccharide & 0 & $4.4 \pm 1.3$ \\
Cholesterol (mg/d) & $422.0 \pm 79.1$ & $179.0 \pm 41.1$ \\
Fiber (g/d) & $11.6 \pm 2.3$ & $15.4 \pm 3.6$ \\
Fatty acid composition (\% of total fatty acids by energy intake) & & \\
Palmitic fatty acids (16:0) & $15.9 \pm 4.4$ & $18.9 \pm 5.8$ \\
Palmitoleic fatty acids (16:1) & $2.1 \pm 0.7$ & $2.0 \pm 0.4$ \\
Stearic fatty acids (18:0) & $6.9 \pm 1.3$ & $7.4 \pm 0.9$ \\
Oleic fatty acids (18:1) & $30.7 \pm 6.5$ & $32.1 \pm 3.7$ \\
Linoleic fatty acids (18:2) & $13.2 \pm 3.3$ & $17.0 \pm 5.1$ \\
\hline
\end{tabular}




\subsection{Blood Collection and Laboratory Analysis}

In the mornings of the day the washout diet started (i.e., at baseline), of the day before the HC/LF diet and of the day after the $\mathrm{HC} / \mathrm{LF}$ diet, 12 hour-fasting venous blood samples were collected between 7:00 and 8:00 a.m., and height, weight, waist circumference, hip circumference, heart rate and blood pressure, including the systolic blood pressure (SBP) and the diastolic blood pressure (DBP) (using a standard mercury sphygmomanometer with 1 of 5 cuff sizes chosen on the basis of the circumference of the participant's arm), were measured. Plasma TG, TC, HDL-C, LDL-C, apolipoprotein A-I (Apo A-I), apolipoprotein B-100 (Apo B-100) and glucose were analyzed using the routine methods described previously [19]. Average value of three independent measurements for each variable was used for statistical analyses. The inter- and intra-assays coefficients of variation were less than $6 \%$. Body mass index $\left(\mathrm{BMI},=\right.$ weight $\left.(\mathrm{kg}) /[\text { height }(\mathrm{m})]^{2}\right)$ and waist-to-hip ratio $[\mathrm{WHR},=$ waist circumference $(\mathrm{cm}) / \mathrm{hip}$ circumference $(\mathrm{cm})]$ were calculated.

\subsection{DNA Extraction and Genotyping}

Genomic DNA was isolated from white blood cells using a DNAout kit (Tiandz, China). Variants of $L P L$ rs326 were identified by polymerase chain reaction (PCR)-restriction fragment length polymorphism (RFLP) analysis, and verified by DNA sequencing. The primer annealing temperatures was $58{ }^{\circ} \mathrm{C}$ and primer sequences were as follows: forward primer, 5'-TACACTAGCAAT GTCTAGCTGA-3'; reverse primer, 5'-TCAGCTTTAGCCCAGAATGC-3'. The amplified 488-bp fragments were digested overnight at $37{ }^{\circ} \mathrm{C}$ with 1 unit of MspI (Fermentas, Vilnius, Lithuania). The resulting DNA fragments were 171 and 317-bp in length for the GG genotype and an intact 488-bp fragment for the AA genotype.

\subsection{Statistical Analysis}

The subjects with minor allele homozygosity and heterozygosity were pooled and designated as the $\mathrm{G}$ allele carriers. The results were expressed as mean \pm standard deviation (S.D.) unless stated otherwise. Normality of data was tested using Shapiro-Wilk test. TG values were log-transformed to normalize their distributions and the transformed values were used in all statistical tests. The $\chi^{2}$ goodness-of-fit test was used to evaluate the Hardy-Weinberg equilibrium. Chi-Square tests were performed to analyze genotype and allele frequencies between the males and the females. Independent-sample $t$-tests were performed to analyze the difference between the subjects with the AA genotype and the $\mathrm{G}$ allele carriers, or between the males and females at baseline and before and after the $\mathrm{HC} / \mathrm{LF}$ diet. Two-tailed paired $t$-tests were performed to analyze the difference between before and after the HC/LF diet. Statistical significance was defined as $p \leq 0.05$. 


\section{Results and Discussion}

\subsection{Results}

3.1.1. Distribution of the Genotypes and Alleles of $L P L$ rs 326

Table 2 shows the genotype and allele frequencies of $L P L$ rs326 in the study population. No deviation from the Hardy-Weinberg Equilibrium was found in the distribution of genotypes $(p=0.075)$. There were no statistical significances in genotype $(p=0.171)$ and allele $(p=0.275)$ frequencies between the males and the females.

Table 2. Allele and genotype frequencies of $L P L$ rs326.

\begin{tabular}{|c|c|c|c|c|c|}
\hline Parameter & Total & Hardy-Weinberg $p$ & Males & Females & $p *$ \\
\hline \multicolumn{6}{|c|}{ Genotype frequency $n(\%)$} \\
\hline AA & $34(60.7)$ & & $16(59.3)$ & $18(62.1)$ & \\
\hline $\mathrm{AG}$ & $16(28.6)$ & 0.075 & $6(22.2)$ & $10(34.5)$ & 0.171 \\
\hline GG & $6(10.7)$ & & $5(18.5)$ & $1(3.4)$ & \\
\hline \multicolumn{6}{|c|}{ Allele frequency $(\%)$} \\
\hline A & 75.0 & & 70.4 & 79.3 & 0.275 \\
\hline G & 25.0 & & 29.6 & 20.7 & \\
\hline
\end{tabular}

Data presented as $n(\%) ;{ }^{*}$ Males $v s$. Females by Chi-Square tests.

\subsubsection{Baseline Anthropometric and Biochemical Characteristics}

Table 3 presents the baseline anthropometric and biochemical characteristics between the subjects with the AA genotype and the $G$ allele carriers of the polymorphism. There were no significant differences of the variables between the subjects with the AA genotype and the G allele carriers in the whole study population.

Table 3. Anthropometric and biochemical characteristics of the subjects.

\begin{tabular}{ccc}
\hline Variables & AA genotype $(\boldsymbol{n}=\mathbf{3 4})$ & G allele carriers $(\boldsymbol{n}=\mathbf{2 2})$ \\
\hline Age $($ years $)$ & $23.29 \pm 1.978$ & $22.27 \pm 1.279$ \\
Females $(n(\%))$ & $18(52.94)$ & $11(50.00)$ \\
BMI $\left(\mathrm{kg} / \mathrm{m}^{2}\right)$ & $20.95 \pm 2.81$ & $21.17 \pm 4.39$ \\
WHR (Waist-to-hip ratio) & $0.85 \pm 0.06$ & $0.87 \pm 0.06$ \\
Heart rate (bpm) & $71.76 \pm 8.71$ & $75.45 \pm 11.23$ \\
Glucose $(\mathrm{mg} / \mathrm{dL})$ & $73.15 \pm 9.02$ & $70.49 \pm 10.34$ \\
SBP $(\mathrm{mmHg})$ & $110.15 \pm 13.00$ & $111.36 \pm 11.57$ \\
DBP $(\mathrm{mmHg})$ & $70.15 \pm 9.25$ & $74.32 \pm 12.28$ \\
TC $(\mathrm{mg} / \mathrm{dL})$ & $151.73 \pm 23.98$ & $150.56 \pm 31.10$ \\
HDL-C (mg/dL) & $65.58 \pm 12.10$ & $63.59 \pm 15.87$ \\
LDL-C (mg/dL) & $69.76 \pm 30.93$ & $70.80 \pm 45.13$ \\
TG $(\mathrm{mg} / \mathrm{dL})$ & $71.64 \pm 33.52$ & $83.84 \pm 55.19$ \\
Apo A-I (mg/dL) & $207.78 \pm 20.42$ & $199.86 \pm 27.13$ \\
Apo B-100 (mg/dL) & $67.28 \pm 21.58$ & $68.52 \pm 18.77$ \\
\hline
\end{tabular}

Data presented as mean \pm S.D. or $n(\%)$; No statistical differences were found in the subjects with the AA genotype and the $\mathrm{G}$ allele carriers. 
3.1.3. Effects of the HC/LF Diet on Lipid Profiles of the Subjects with Different Genotypes of $L P L$ rs 326

Table 4 shows the anthropometric variables and lipid profiles of the males and the females with different $L P L$ rs326 genotypes at baseline and before and after the HC/LF diet. No significant differences were found between the $\mathrm{G}$ allele carriers and the AA homozygotes at baseline, before the $\mathrm{HC} / \mathrm{LF}$ diet or after the HC/LF diet in males and females separately. However, the males had higher levels of WHR and lower levels of Apo A-I than the females regardless of the genotype constantly at baseline and before and after the HC/LF diet. The male G carriers had lower levels of HDL-C than the female $\mathrm{G}$ carriers constantly at baseline and before and after the $\mathrm{HC} / \mathrm{LF}$ diet, and the males with the AA genotype had a lower level of HDL-C than the females with the same genotype only at baseline. The males with the AA genotype had lower TC and the male G carriers had lower LDL-C than the female counterparts only after the $\mathrm{HC} / \mathrm{LF}$ diet.

When compared with those before the HC/LF diet, the male G carriers had significantly increased HDL-C and Apo A-I after the HC/LF diet. TC was significantly decreased regardless of the genotype and gender, and TG significantly increased in all the females after the HC/LF diet. Meanwhile, LDL-C was decreased in all the subjects, although the decrease was not statistically significant in the female $G$ carriers. BMI was decreased in the males with the AA genotype, while glucose decreased in the female $\mathrm{G}$ carriers after the HC/LF diet. In addition, there were no statistically significant differences in Apo B-100 regardless of gender and the genotype between before and after the HC/LF diet.

\subsection{Discussion}

Although the risk of CAD has been steadily increased in younger populations over the past few decades [17], much less studies have been made in this population. While dietary intervention has become an effective method of primordial prevention on dyslipidemia [23], the HC/LF diet was found to have different effects on plasma lipids in different subjects [19,24]. The mechanism of the discrepancy has not been elucidated yet. In the current study, plasma lipid profiles were investigated in healthy young Chinese Han subjects with different genotypes of $L P L$ rs326 at baseline and before and after the HC/LF diet. Since the effect of this polymorphism could be minor and concealed by the confounders, plasma lipids and Apos of the individuals were compared by paired-samples $t$-tests between before and after the HC/LF diet. Conceivably, other genetic and environmental factors affecting lipids metabolism would remain constant for each individual, especially in such a short time of 6 days of the HC/LF diet. Therefore, the differences of lipid profile responses to the HC/LF diet were most likely attributed to the specific genetic background of individuals [24]. The results showed that the G allele of LPL rs326 was associated with elevated levels of HDL-C and Apo A-I after the $\mathrm{HC} / \mathrm{LF}$ diet in the males of healthy Chinese Han Youth. These results suggest that the HC/LF diet interacts with the variants of $L P L$ rs 326 to influence lipid profiles in the healthy Chinese Han youth. 
Table 4. Anthropometric parameters, glucose, lipids and apolipoproteins of the male and female subjects with different $L P L$ rs326 genotypes at baseline and before and after the $\mathrm{HC} / \mathrm{LF}$ diet.

\begin{tabular}{|c|c|c|c|c|}
\hline \multirow[b]{2}{*}{ Variables } & \multicolumn{2}{|c|}{ Males } & \multicolumn{2}{|c|}{ Females } \\
\hline & $\begin{array}{l}\text { AA genotype } \\
\quad(n=16)\end{array}$ & $\begin{array}{l}G \text { allele carriers } \\
\qquad(n=11)\end{array}$ & $\begin{array}{l}\text { AA genotype } \\
\qquad(n=18)\end{array}$ & $\begin{array}{l}\text { G allele carriers } \\
\qquad(n=11)\end{array}$ \\
\hline Age (years) & $23.50 \pm 2.03$ & $22.18 \pm 1.60$ & $23.11 \pm 1.97$ & $22.36 \pm 0.92$ \\
\hline \multicolumn{5}{|l|}{$\mathrm{BMI}\left(\mathrm{kg} / \mathrm{m}^{2}\right)$} \\
\hline Baseline & $21.44 \pm 3.02$ & $22.48 \pm 5.47$ & $20.53 \pm 2.62$ & $19.85 \pm 2.59$ \\
\hline Before $\mathrm{HC} / \mathrm{LF}$ diet & $21.29 \pm 3.00$ & $22.35 \pm 5.47$ & $20.33 \pm 2.62$ & $19.82 \pm 2.51$ \\
\hline After HC/LF diet & $21.17 \pm 2.95^{* *}$ & $22.23 \pm 5.48$ & $20.23 \pm 2.67$ & $19.71 \pm 2.33$ \\
\hline \multicolumn{5}{|l|}{$\begin{array}{l}\text { WHR (Waist-to-hip } \\
\text { ratio) }\end{array}$} \\
\hline Baseline & $0.88 \pm 0.05$ & $0.90 \pm 0.06$ & $0.82 \pm 0.05^{*}$ & $0.83 \pm 0.04 *$ \\
\hline Before $\mathrm{HC} / \mathrm{LF}$ diet & $0.89 \pm 0.04$ & $0.91 \pm 0.05$ & $0.83 \pm 0.03^{*}$ & $0.83 \pm 0.06^{*}$ \\
\hline After HC/LF diet & $0.90 \pm 0.05$ & $0.91 \pm 0.05$ & $0.83 \pm 0.03 *$ & $0.84 \pm 0.04 *$ \\
\hline \multicolumn{5}{|l|}{ Glucose (mg/dL) } \\
\hline Baseline & $74.64 \pm 8.59$ & $68.10 \pm 9.90$ & $71.83 \pm 9.42$ & $72.89 \pm 10.68$ \\
\hline Before $\mathrm{HC} / \mathrm{LF}$ diet & $79.64 \pm 10.32$ & $83.37 \pm 7.17$ & $78.00 \pm 10.49$ & $81.35 \pm 7.21$ \\
\hline After HC/LF diet & $78.27 \pm 5.28$ & $78.02 \pm 8.09$ & $77.46 \pm 8.42$ & $77.45 \pm 5.07^{* *}$ \\
\hline \multicolumn{5}{|l|}{$\mathrm{TG}(\mathrm{mg} / \mathrm{dL})$} \\
\hline Baseline & $80.31 \pm 38.91$ & $101.14 \pm 73.20$ & $64.41 \pm 27.32$ & $66.55 \pm 19.52$ \\
\hline Before $\mathrm{HC} / \mathrm{LF}$ diet & $78.14 \pm 27.82$ & $86.42 \pm 49.54$ & $67.61 \pm 16.61$ & $62.41 \pm 15.20$ \\
\hline After HC/LF diet & $87.31 \pm 36.29$ & $88.09 \pm 44.03$ & $81.52 \pm 25.25^{* *}$ & $75.48 \pm 20.12^{* *}$ \\
\hline \multicolumn{5}{|l|}{$\mathrm{TC}(\mathrm{mg} / \mathrm{dL})$} \\
\hline Baseline & $147.08 \pm 23.97$ & $145.14 \pm 25.93$ & $155.61 \pm 23.97$ & $155.48 \pm 35.67$ \\
\hline Before $\mathrm{HC} / \mathrm{LF}$ diet & $149.04 \pm 24.01$ & $145.15 \pm 23.61$ & $158.51 \pm 29.46$ & $162.38 \pm 22.98$ \\
\hline After HC/LF diet & $116.59 \pm 18.02^{* * *}$ & $117.76 \pm 21.92^{* * *}$ & $131.36 \pm 19.43^{*, * * *}$ & $133.38 \pm 23.01^{* * * *}$ \\
\hline \multicolumn{5}{|l|}{ LDL-C (mg/dL) } \\
\hline Baseline & $70.53 \pm 36.53$ & $61.70 \pm 52.02$ & $69.11 \pm 26.47$ & $79.90 \pm 37.26$ \\
\hline Before $\mathrm{HC} / \mathrm{LF}$ diet & $63.90 \pm 21.65$ & $68.84 \pm 24.66$ & $70.11 \pm 21.61$ & $71.37 \pm 20.67$ \\
\hline After HC/LF diet & $55.13 \pm 11.08^{* *}$ & $54.28 \pm 10.76^{* *}$ & $63.10 \pm 14.77^{* *}$ & $64.20 \pm 10.98^{*}$ \\
\hline \multicolumn{5}{|l|}{ HDL-C (mg/dL) } \\
\hline Baseline & $60.33 \pm 9.37$ & $53.95 \pm 12.89$ & $69.96 \pm 12.58$ * & $73.23 \pm 12.59$ * \\
\hline Before $\mathrm{HC} / \mathrm{LF}$ diet & $53.23 \pm 11.70$ & $46.96 \pm 8.26$ & $60.71 \pm 10.70$ & $59.44 \pm 9.05^{*}$ \\
\hline After HC/LF diet & $56.65 \pm 9.70$ & $51.18 \pm 10.61^{* *}$ & $63.16 \pm 11.08$ & $61.09 \pm 6.20^{*}$ \\
\hline \multicolumn{5}{|l|}{ Apo A-I (mg/dL) } \\
\hline Baseline & $199.79 \pm 23.59$ & $185.00 \pm 28.94$ & $214.00 \pm 15.53^{*}$ & $213.36 \pm 17.25^{*}$ \\
\hline Before $\mathrm{HC} / \mathrm{LF}$ diet & $173.00 \pm 28.46$ & $159.45 \pm 23.57$ & $191.61 \pm 24.11^{*}$ & $193.55 \pm 20.26^{*}$ \\
\hline After HC/LF diet & $173.81 \pm 24.06$ & $165.64 \pm 28.09^{* *}$ & $195.33 \pm 20.09$ * & $197.91 \pm 25.50 *$ \\
\hline \multicolumn{5}{|l|}{ Apo B-100 (mg/dL) } \\
\hline Baseline & $66.50 \pm 24.85$ & $65.00 \pm 20.67$ & $67.89 \pm 19.39$ & $71.73 \pm 17.23$ \\
\hline Before $\mathrm{HC} / \mathrm{LF}$ diet & $56.25 \pm 18.11$ & $60.55 \pm 23.24$ & $58.00 \pm 17.02$ & $61.00 \pm 16.08$ \\
\hline After HC/LF diet & $54.75 \pm 19.49$ & $60.55 \pm 23.98$ & $57.78 \pm 15.92$ & $61.64 \pm 18.32$ \\
\hline
\end{tabular}

Data presented as mean \pm S.D.; ${ }^{*} p<0.05$, compared with that of the male with same genotype by independent-samples $t$-tests; ${ }^{* *} p<0.05$, compared with that before the HC/LF diet in the same genotype by paired-samples $t$-tests; ${ }^{* * *} p<0.001$, compared with that before the HC/LF diet in the same genotype by paired-samples $t$-tests. No significantly differences were found between the $\mathrm{G}$ allele carriers and the AA homozygotes at baseline, before the $\mathrm{HC} / \mathrm{LF}$ diet or after the $\mathrm{HC} / \mathrm{LF}$ diet. 
A number of studies reported discrepant effects of $\mathrm{HC} / \mathrm{LF}$ diets containing different types of carbohydrates on lipid profiles [6,25]. The traditional Chinese diet mainly consists of white rice, in which most of the carbohydrate is starch [26]. An association was found between diets containing high starch and lower TC and LDL-C in several studies [27,28]. However, the effects of the high-starch diets on HDL-C and TG were inconsistent [27-30]. In the present study, we presented significantly increased levels of HDL-C and Apo A-I in the males with the G allele of $L P L$ rs326 after the HC/LF diet (Table 4). In addition, no parallel changes were found of their confounders including age, BMI, WHR and plasma levels of glucose (Table 4). Therefore, this finding suggests that the $\mathrm{G}$ allele of $L P L$ rs 326 could interact with the HC/LF diet to elevate the level of HDL-C in healthy Chinese males in their early 20s. Since this polymorphism is in the intron 8 of $L P L$, it is very unlikely that this is a functional mutation [16]. One possibility is that this polymorphism is in linkage disequilibrium with some other functional mutations. For example, $L P L$ rs 326 was found in linkage disequilibrium with $L P L$ rs328 in European population. Similarly, we also found the linkage disequilibrium $\left(D^{\prime}=0.990, \mathrm{r}^{2}=0.414\right.$ ) between $\mathrm{rs} 326$ and rs328 in 724 Chinese Han subjects in a cross-sectional study (data not shown). The rs328 mutation regarded as a gain-of-function mutation is associated with the anti-atherogenic lipid profiles [31]. In addition, the elevated HDL-C level after the HC/LF diet might also be due to the adaptation to long-term effects of high carbohydrate diets in this population. It is well known that people in China generally have high dietary carbohydrate intake [6,7] and more favorable lipid profiles, including a higher HDL-C level $[32,33]$. Taken together, young Chinese males with $L P L$ rs326 G allele might be more adaptable to the increase of dietary carbohydrate than those with the AA genotype.

Another important finding of the present study was that when compared with that before the HC/LF diet, there was a significantly increased level of plasma TG in the females after the HC/LF diet, which might be attributable to their higher levels of estrogen. It is indicated that HC/LF diets can adversely increase the plasma concentrations of TG [6] which are mainly hydrolyzed by the key enzyme LPL. However, high levels of estrogen in females significantly inhibit the activity of LPL and retard the hydrolysis of TG by LPL [34].

In the present study, all subjects experienced statistically significantly decreased levels of TC after the $\mathrm{HC} / \mathrm{LF}$ diet compared to before the HC/LF diet. For LDL-C, there was a statistically significant reduction after the $\mathrm{HC} / \mathrm{LF}$ diet in the subjects, except for the female $\mathrm{G}$ carriers. However, a trend toward reduced level (from $71.37 \mathrm{mg} / \mathrm{dL}$ to $64.20 \mathrm{mg} / \mathrm{dL}$ ) was also observed in the female $\mathrm{G}$ carriers. Furthermore, $L P L$ is located at chromosome 8p22 [35], a region associated with serum TG and HDL-C levels (http://omim.org/entry/609708). Jackson et al. [36] reported that plasma postheparin LPL activity was associated with changes in serum lipid concentrations, especially TG and HDL-C. All these imply that $L P L$ rs326 might not be directly associated to the reduced levels of TC and LDL-C induced by the $\mathrm{HC} / \mathrm{LF}$ diet.

\section{Conclusions}

In summary, our results suggest that the $\mathrm{G}$ allele of $L P L$ rs 326 be associated with increased levels of HDL-C and Apo A-I after the HC/LF diet in the healthy young Chinese Han subjects. Although the analyses were based on a small sample size and thus suggestive, the findings justify the need for future 
studies with larger sample sizes, which will pave the way to personalized dietary intervention to reduce risks of AS and related vascular diseases in China, a country with a quarter of the worlds' population.

\section{Acknowledgments}

The study was supported by the National Natural Science Foundation of China (Grant No. 81370375). Ding Zhi Fang is the recipient of the grant.

\section{Author Contributions}

Xing Chun Zhu, Jia Lin and Qian Wang carried out the study. Xing Chun Zhu, Hui Liu and Li Qiu analyzed the data and prepared the manuscript. Xing Chun Zhu and Ding Zhi Fang revised the final version of the manuscript. Ding Zhi Fang had the original idea for the study and, with all co-authors carried out the design. All authors read and approved the final manuscript.

\section{Conflicts of Interest}

All authors declare no conflict of interests.

\section{References}

1. Kones, R. Primary prevention of coronary heart disease: Integration of new data, evolving views, revised goals, and role of rosuvastatin in management. A comprehensive survey. Drug Des. Devel. Ther. 2011, 5, 325-380.

2. Driscoll, A.; Beltrame, J.; Beauchamp, A.; Morgan, C.; Weekes, A.; Tonkin, A. Reducing risk in coronary artery disease. Are Australian patients in general practice achieving targets? The CADENCE Study. Intern. Med. J. 2013, 43, 526-531.

3. Kim, H.K.; Chang, S.A.; Choi, E.K.; Kim, Y.J.; Kim, H.S.; Sohn, D.W.; Oh, B.H.; Lee, M.M.; Park, Y.B.; Choi, Y.S. Association between plasma lipids, and apolipoproteins and coronary artery disease: A cross-sectional study in a low-risk Korean population. Int. J. Cardiol. 2005, 101, 435-440.

4. Satoh, H.; Nishino, T.; Tomita, K.; Tsutsui, H. Fasting triglyceride is a significant risk factor for coronary artery disease in middle-aged Japanese men. Circ. J. 2006, 70, 227-231.

5. Jacobson, T.A.; Miller, M.; Schaefer, E.J. Hypertriglyceridemia and cardiovascular risk reduction. Clin. Ther. 2007, 29, 763-777.

6. Parks, E.J.; Hellerstein, M.K. Carbohydrate-induced hypertriacylglycerolemia: Historical perspective and review of biological mechanisms. Am. J. Clin. Nutr. 2000, 71, 412-433.

7. Chen, Z.; Shu, X.-O.; Yang, G.; Li, H.; Li, Q.; Gao, Y.-T.; Zheng, W. Nutrient intake among Chinese women living in Shanghai, China. Br. J. Nutr. 2006, 96, 393-399.

8. Gaziano, T.A.; Bitton, A.; Anand, S.; Abrahams-Gessel, S.; Murphy, A. Growing epidemic of coronary heart disease in low- and middle-income countries. Curr. Probl. Cardiol. 2010, 35, 72-115.

9. Khor, G.L. Cardiovascular epidemiology in the Asia-Pacific region. Asia Pac. J. Clin. Nutr. 2001, $10,76-80$. 
10. Mead, J.R.; Irvine, S.A.; Ramji, D.P. Lipoprotein lipase: Structure, function, regulation, and role in disease. J. Mol. Med. 2002, 80, 753-769.

11. Henderson, H.E.; Kastelein, J.J.; Zwinderman, A.H.; Gagne, E, Jukema, J.W.; Reymer, P.W.; Groenemeyer, B.E.; Lie, K.I.; Bruschke, A.V.; Hayden, M.R.; et al. Lipoprotein lipase activity is decreased in a large cohort of patients with coronary artery disease and is associated with changes in lipids and lipoproteins. J. Lipid Res. 1999, 40, 735-743.

12. Rip, J.; Nierman, M.C.; Wareham, N.J.; Luben, R.; Bingham, S.A.; Day, N.E.; van Miert, J.N.; Hutten, B.A.; Kastelein, J.J.; Kuivenhoven, J.A.; et al. Serum lipoprotein lipase concentration and risk for future coronary artery disease: The EPIC-Norfolk prospective population study. Arterioscler. Thromb. Vasc. Biol. 2006, 26, 637-642.

13. Rebhi, L.; Kchok, K.; Omezzine, A.; Kacem, S.; Rejeb, J.; Ben Hadjmbarek, I.; Belkahla, R.; Boumaiza, I.; Moussa, A.; Ben Rejeb, N.; et al. Six lipoproteinlipase gene polymorphisms, lipid profile and coronary stenosis in a Tunisian population. Mol. Biol. Rep. 2012, 39, 9893-9901.

14. Tang, W.; Apostol, G.; Schreiner, P.J.; Jacobs, D.R.J.; Boerwinkle, E.; Fornage, M. Associations of lipoprotein lipase gene polymorphisms with longitudinal plasma lipid trends in young adults: The CARDIA Study. Circ. Cardiovasc. Genet. 2010, 3, 179-186.

15. Bhanushali, A.A.; Das, B.R. Genetic variants at the APOE, lipoproteinlipase (LpL), cholesteryl ester transfer protein (CETP), and endothelial nitric oxide (eNOS) genes and coronary artery disease (CAD): CETP Taq1 B2B2 associates with lower risk of CAD in Asian Indians. J. Community Genet. 2010, 1, 55-62.

16. Liu, Y.; Zhou, D.; Zhang, Z.; Song, Y.; Zhang, D.; Zhao, T.; Chen, Z.; Sun, Y.; Zhang, D.; Yang, Y.; et al. Effects of genetic variants on lipid parameters and dyslipidemia in a Chinese population. J. Lipid Res. 2011, 52, 354-360.

17. Saleheen, D.; Frossard, P. CAD risk factors and acute myocardial infarction in Pakistan. Acta Cardiol. 2004, 59, 417-424.

18. Fonseca, N.; Bernardino, L.; Silvestre, I.; Santos, J.; Seixo, F.; Mendes, L.; Inês, L. Acute myocardial infarction in patients aged under 45 years. Rev. Port. Cardiol. 2004, 23, 1585-1591.

19. Huang, X.; Gong, R.; Lin, J.; Li, R.; Xiao, L.; Duan, W.; Fang, D. Effects of lipoprotein lipase gene variations, a high-carbohydrate low-fat diet, and gender on serum lipid profiles in healthy Chinese Han youth. Biosci. Trends 2011, 5, 198-204.

20. Schwarz, J.M.; Linfoot, P.; Dare, D.; Aghajanian, K. Hepatic de novo lipogenesis in normoinsulinemic and hyperinsulinemic subjects consuming high-fat, low-carbohydrate and low-fat, high-carbohydrate isoenergetic diets. Am. J. Clin. Nutr. 2003, 77, 43-50.

21. Leclerc, I.; Davignon, I.; Lopez, D.; Garrel, D.R. No change in glucose tolerance and substrate oxidation after a high-carbohydrate, low-fat diet. Metabolism 1993, 42, 365-370.

22. Chen, A.K.; Roberts, C.K.; Barnard, R.J. Effect of a short-term diet and exercise intervention on metabolic syndrome in overweight children. Metabolism 2006, 55, 871-878.

23. Andersen, C.J.; Fernandez, M.L. Dietary strategies to reduce metabolic syndrome. Rev. Endocr. Metab. Disord. 2013, 14, 241-254.

24. Du, J.; Fang, D.Z.; Lin, J.; Xiao, L.Y.; Zhou, X.D.; Shigdar, S.; Duan, W. TaqIB polymorphism in the CETP gene modulates the impact of HC/LF diet on the HDL profile in healthy Chinese young adults. Nutr. Biochem. 2010, 21, 1114-1119. 
25. Lichtenstein, A.H. Dietary fat, carbohydrate, and protein: Effects on plasma lipoprotein patterns. J. Lipid Res. 2006, 47, 1661-1667.

26. Chen, C.-M.; Zhao, W.; Yang, Z.; Zhai, Y.; Wu, Y.; Kong, L. The role of dietary factors in chronic disease control in China. Obes. Rev. 2008, 9, 100-103.

27. Marckmann, P.; Raben, A.; Astrup, A. Ad libitum intake of low-fat diets rich in either starchy foods or sucrose: Effects on blood lipids, factor VII coagulant activity, and fibrinogen. Metabolism 2000, 49, 731-735.

28. Surwit, R.S.; Feinglos, M.N.; McCaskill, C.C; Clay, S.L.; Babyak, M.A.; Brownlow, B.S.; Plaisted, C.S.; Lin, P.H. Metabolic and behavioral effects of a high-sucrose diet during weight loss. Am. J. Clin. Nutr. 1997, 65, 908-915.

29. Raben, A.; Holst, J.J.; Madsen, J.; Astrup, A. Diurnal metabolic profiles after $14 \mathrm{~d}$ of an ad libitum high-starch, high-sucrose, or high-fat diet in normal-weight never-obese and postobese women. Am. J. Clin. Nutr. 2001, 73, 177-189.

30. Gerhardt, A.L.; Gallo, N.B. Full-fat rice bran and oat bran similarly reduce hypercholesterolemia in humans. J. Nutr. 1998, 128, 865-869.

31. Rip, J.; Nierman, M.C.; Ross, C.J.; Jukema, J.W.; Hayden, M.R.; Kastelein, J.J.; Stroes, E.S.; Kuivenhoven, J.A. Lipoprotein lipase S447X a naturally occurring gain-of-function mutation. Arterioscler. Thromb. Vasc. Biol. 2006, 26, 1236-1245.

32. Cai, H.J.; Li, Z.X.; Yang, S.M. Serum high density lipoprotein cholesterol levels in Chinese healthy subjects and patients with certain diseases. Atherosclerosis 1982, 43, 197-207.

33. McGladdery, S.H.; Pimstone, S.N.; Clee, S.M.; Bowden, J.F.; Hayden, M.R.; Frohlich, J.J. Common mutations in the lipoprotein lipase gene (LPL): Effects on HDL cholesterol levels in a Chinese Canadian population. Atherosclerosis 2001, 156, 401-407.

34. Price, T.M.; O’Brien, S.N.; Welter, B.H.; George, R.; Anandjiwala, J.; Kilgore, M. Estrogen regulation of adipose tissue lipoprotein lipase-Possible mechanism of body fat distribution. Am. J. Obstet. Gynecol. 1998, 178, 101-107.

35. Kim, J.W.; Cheng, Y.; Liu, W.; Li, T.; Yegnasubramanian, S.; Zheng, S.L.; Xu, J.; Isaacs, W.B.; Chang, B.L. Genetic and epigenetic inactivation of LPL gene in human prostate cancer. Int. J. Cancer. 2009, 124, 734-738.

36. Jackson, R.L.; Yates, M.T.; McNerney, C.A.; Kashyap, M.L. Relationship between post-heparin plasma lipases, triglycerides and high density lipoproteins in normal subjects. Horm. Metab. Res. 1990, 22, 289-294.

(C) 2014 by the authors; licensee MDPI, Basel, Switzerland. This article is an open access article distributed under the terms and conditions of the Creative Commons Attribution license (http://creativecommons.org/licenses/by/3.0/). 